\title{
Mass absorption efficiency of elemental carbon and water-soluble organic carbon in Beijing, China
}

\author{
Y. Cheng ${ }^{1}$, K.-B. He ${ }^{1}$, M. Zheng ${ }^{2}$, F.-K. Duan ${ }^{1}$, Z.-Y. Du ${ }^{1}$, Y.-L. Ma ${ }^{1}$, J.-H. Tan ${ }^{3}$, F.-M. Yang ${ }^{3}$, J.-M. Liu ${ }^{4}$, \\ X.-L. Zhang ${ }^{4}$, R. J. Weber ${ }^{4}$, M. H. Bergin ${ }^{4,5}$, and A. G. Russell ${ }^{5}$ \\ ${ }^{1}$ State Key Joint Laboratory of Environment Simulation and Pollution Control, School of Environment, Tsinghua University, \\ Beijing, China \\ ${ }^{2}$ College of Environmental Sciences and Engineering, Peking University, Beijing, China \\ ${ }^{3}$ Key Laboratory of Computational Geodynamics, College of Earth Science, Graduate University of Chinese Academy of \\ Sciences, Beijing, China \\ ${ }^{4}$ School of Earth and Atmospheric Sciences, Georgia Institute of Technology, Atlanta, Georgia, USA \\ ${ }^{5}$ School of Civil and Environmental Engineering, Georgia Institute of Technology, Atlanta, Georgia, USA
}

Received: 29 June 2011 - Published in Atmos. Chem. Phys. Discuss.: 2 September 2011

Revised: 12 November 2011 - Accepted: 16 November 2011 - Published: 18 November 2011

\begin{abstract}
The mass absorption efficiency (MAE) of elemental carbon (EC) in Beijing was quantified using a thermaloptical carbon analyzer. The MAE measured at $632 \mathrm{~nm}$ was $8.45 \pm 1.71$ and $9.41 \pm 1.92 \mathrm{~m}^{2} \mathrm{~g}^{-1}$ during winter and summer respectively. The daily variation of MAE was found to coincide with the abundance of organic carbon (OC), especially the $\mathrm{OC}$ to $\mathrm{EC}$ ratio, perhaps due to the enhancement by coating with organic aerosol (especially secondary organic aerosol, SOA) or the artifacts resulting from the redistribution of liquid-like organic particles during the filterbased absorption measurements. Using a converting approach that accounts for the discrepancy caused by measurements methods of both light absorption and EC concentration, previously published MAE values were converted to the equivalent-MAE, which is the estimated value if using the same measurement methods as used in this study. The equivalent-MAE was found to be much lower in the regions heavily impacted by biomass burning (e.g., below $2.7 \mathrm{~m}^{2} \mathrm{~g}^{-1}$ for two Indian cities). Results from source samples (including diesel exhaust samples and biomass smoke samples) also demonstrated that emissions from biomass burning would decrease the MAE of EC. Moreover, optical properties of water-soluble organic carbon (WSOC) in Beijing were presented. Light absorption by WSOC exhibited strong wavelength $(\lambda)$ dependence such that absorption varied approximately as $\lambda^{-7}$, which was characteristic of the brown car-
\end{abstract}

Correspondence to: K. B. He (hekb@tsinghua.edu.cn) bon spectra. The MAE of WSOC (measured at $365 \mathrm{~nm}$ ) was $1.79 \pm 0.24$ and $0.71 \pm 0.20 \mathrm{~m}^{2} \mathrm{~g}^{-1}$ during winter and summer respectively. The large discrepancy between the MAE of WSOC during winter and summer was attributed to the difference in the precursors of SOA such that anthropogenic volatile organic compounds (AVOCs) should be more important as the precursors of SOA in winter. The MAE of WSOC in Beijing was much higher than results from the southeastern United States which were obtained using the same method as used in this study, perhaps due to the stronger emissions of biomass burning in China.

\section{Introduction}

Carbonaceous aerosol has been the focus of extensive studies during the last decade due to its complex effects on human health, visibility and climate change. Carbonaceous aerosol is an aggregate of thousands of poorly characterized species with a wide range of chemical, thermal and optical properties (Pöschl, 2005; Andreae and Gelencsér, 2006). As a result, its characterization is more difficult and complex compared with other components in ambient aerosol (e.g., sulphate and mineral dust). Though it is still impossible to completely identify carbonaceous aerosol on a molecular level, a variety of techniques has been developed to classify it into different fractions resulting in several "instrument-operational definitions" which are usually not congruent. In speciation monitoring, carbonaceous aerosol is commonly divided into

Published by Copernicus Publications on behalf of the European Geosciences Union. 
organic carbon (OC) and elemental carbon (EC) by thermaloptical (or thermal) method (Chow et al., 1993; Birch and Cary, 1996). Another widely used definition is black carbon (BC), which is the light-absorbing carbon measured by optical instruments such as Aethalometer (Hansen and Novakov, 1990). In the emission-inventory and climate-science community, black carbon is usually used synonymously with $\mathrm{EC}$, because the emission factors of $\mathrm{BC}$ are typically measured by thermal-optical (or thermal) methods (e.g., Chen et al., 2009). Recently, scientific attention has shifted from the role of black carbon as a pollutant to its importance as a driver of global warming (Jacobson, 2001; Ramanathan and Carmichael, 2008). Moreover, atmospheric heating caused by black carbon may affect the large scale circulation and the hydrological cycle with significant regional climate effects that contribute to the observed precipitation and temperature changes in China (Ramanathan et al., 2001; Menon et al., 2002).

The mass absorption efficiency (MAE, $\mathrm{m}^{2} \mathrm{~g}^{-1}$ ), a parameter characterizing the optical properties of black carbon, is defined as:

$\operatorname{MAE}\left(\mathrm{m}^{2} \mathrm{~g}^{-1}\right)=\frac{b_{\mathrm{abs}}}{\mathrm{BC}}$

where $b_{\mathrm{abs}}$ and $\mathrm{BC}$ is the absorption coefficient $\left(\mathrm{Mm}^{-1}\right)$ and mass concentration of black carbon $\left(\mu \mathrm{g} \mathrm{m}^{-3}\right)$ respectively (Liousse et al., 1993). When calculating MAE by Eq. (1), EC measured by thermal-optical (or thermal) method is typically used as BC, and absorption measurements have most frequently been performed by filter-based techniques (e.g., Aethalometer) which measure the change in the light transmittance through a filter due to the deposition of airborne particles (Sharma et al., 2002; Jeong et al., 2004; Snyder and Schauer, 2007; Knox et al., 2009; Chan et al., 2010). However, significant artifacts are associated with the filterbased method, due to the aerosol-filter interactions, shadowing of the incident light with increasing filter loading, and aerosol scattering effects (Arnott et al., 2003; Weingartner et al., 2003; Petzold et al., 2005; Sandradewi et al., 2008). For example, results from downtown Toronto showed a constant ratio of $2.4 \pm 0.15$ between the MAE values retrieved from Aethalometer and photoacoustic spectrometer (PAS) which can measure light absorption directly on airborne particles (Knox et al., 2009). However, another recent study found that the ratio of $b_{a b s}$ measured by the Particle Soot Absorption Photometer (PSAP, also a filter-based method) to that measured by the PAS depended on the abundance of organic aerosol (OA) such that the ratio was increased by about $8 \%$ for every $1 \mu \mathrm{g} \mathrm{m}^{-3}$ increase in OA; and the ratio was estimated to be 1.12, 1.40 and 1.69 for rural, urban and heavily polluted regions respectively; moreover, the ratio was found to correlate more strongly with the $\mathrm{OA}$ to $\mathrm{BC}$ ratio rather than just OA concentration (Lack et al., 2008). Similar results were also observed in a companion laboratory study (Cappa et al., 2008a). Another concern in the determination of MAE is the influence of mixing state (Schnaiter et al., 2003, 2005; Bond et al., 2006). When BC is internally mixed with other components such as sulphate and organic carbon, the coatings can focus light into the $\mathrm{BC}$ core of the particle which would increase the MAE value (Bergstrom et al., 1982). Enhancement of MAE by coating can be described by absorption amplification. Laboratory studies showed that the amplification factor was 1.8 2.1 for diesel soot particles when coated with secondary organic carbon produced by the oxidation of $\alpha$-pinene (Schnaiter et al., 2005), whereas the amplification factor was estimated to be $3 \sim 6$ during a field campaign conducted at Jeju Island, South Korea (Flowers et al., 2010). The effects of coatings can also be evaluated by using a thermal-denuder which volatilizes the coatings (or a fraction of the coatings) by heating the airborne aerosol before absorption measurement. For example, Knox et al. (2009) found that the MAE of freshly emitted BC, which was calculated based on Aethalometer at $880 \mathrm{~nm}$, was reduced by about $25 \%$ (from 19.3 to $14.4 \mathrm{~m}^{2} \mathrm{~g}^{-1}$ ) after heating.

Black carbon is typically treated as the only lightabsorbing species in climate models (Kirchstetter et al., 2004). However, it has been recently made clear that certain organic carbon species in addition to black carbon may also contribute to light absorption by atmospheric aerosols, indicating a continuum of carbonaceous components in optical properties (Pöschl, 2005; Andreae and Gelencsér, 2006). Light absorbing organic aerosol is usually termed brown carbon. Sources of brown carbon include residential coal combustion (Bond, 2001), biomass burning (Kirchstetter et al., 2004; Clarke et al., 2007; Bergstrom et al., 2007; Zhang et al., 2010), biogenic materials (Andreae and Crutzen, 1997), and atmospheric reactions (Gelencsér et al., 2003; Hecobian et al., 2010). Laboratory studies also provide additional evidence for the presence of brown carbon (Schnaiter et al., 2006; Chakrabarty et al., 2006, 2010). Brown carbon is strongly associated with the humic-like substances (HULIS, Hoffer et al., 2006), whereas the "tar balls", which have been widely observed in Africa, Europe (Pósfai et al., 2004), North America (Hand et al., 2005) and Asia (Alexander et al., 2008), are recognized as another important type of brown carbon. The mass absorption efficiency of brown carbon increases sharply from long to short wavelengths, resulting in its brown appearance (Alexander et al., 2008). Absorption of ultraviolet (UV) light by brown carbon is important since UV irradiance significantly affects the tropospheric ozone production and photochemistry (Jacobson, 1999). Moreover, a significant fraction of brown carbon is water-soluble (Hoffer et al., 2006). Dissolution of brown carbon into cloud droplets could result in homogeneous absorbing droplets that affect the overall cloud absorption, especially in the UV range, indicating that brown carbon might have important influence on climate (Andreae and Gelencsér, 2006).

The radiative forcing of carbonaceous aerosol is one of the difficult challenges in climate modeling. Substantial uncertainties are due to the complexity in optical parameters of EC 
in the real atmosphere and the presence of light-absorbing organic carbon which is still poorly understood. In this study, optical properties of carbonaceous aerosol in Beijing, a representative mega city in East Asia, are presented. The MAE of EC is quantified using a thermal-optical carbon analyzer. A converting approach that accounts for the discrepancy caused by the measurement methods of both light absorption and EC concentration is also developed. Moreover, light absorption characteristics of the $\mathrm{PM}_{2.5}$ water extracts are presented.

\section{Methods}

\subsection{Sample collection}

\subsubsection{Ambient samples}

Ambient $\mathrm{PM}_{2.5}$ samples were collected by a five-channel Spiral Ambient Speciation Sampler (SASS, MetOne Inc.) at the Tsinghua University campus in Beijing. Tsinghua University is located in the urban area of Beijing, about $12 \mathrm{~km}$ northwest of the city center. There are no major industrial sources around the campus. Twenty-nine and thirty sets of daily $\mathrm{PM}_{2.5}$ samples were collected during winter and summer of 2009, respectively. Parallel quartz filters (denuded) and Teflon filters (un-denuded) were used in the present study. Detailed operating configuration of the SASS sampler during each sampling period was described by Cheng et al. (2010). The activated carbon denuder (provided by MetOne) is $20 \mathrm{~mm}$ long and $38 \mathrm{~mm}$ in diameter with about 1000 of $1 \mathrm{~mm} \times 1 \mathrm{~mm}$ channels. A new denuder was used for each sampling campaign. The denuder efficiency for removing the positive artifact was demonstrated to be $100 \%$ throughout each sampling period; particle loss due to diffusion to the walls of the denuder, volatilization of particulate organic carbon during transportation through the denuder, and the shedding of the denuder material were also shown to be negligible (Cheng et al., 2010).

The quartz (2500 QAT-UP) and Teflon (R2PJ047) filters were from Pall Corp. (Ann Arbor, MI), and were $47 \mathrm{~mm}$ in diameter. The face velocity was $9.8 \mathrm{~cm} \mathrm{~s}^{-1}$ at the operating flow rate $\left(6.7 \mathrm{~L} \mathrm{~min}^{-1}\right)$. All of the quartz and Teflon filters used throughout each campaign were taken from the same lot. The quartz filters were pre-baked at $550^{\circ}$ in air for $24 \mathrm{~h}$, whereas the Teflon filters were used as received from the manufacturer. Twenty-nine quartz filters were kept as filter blanks. The OC concentrations of the blank filters averaged $0.44 \pm 0.15 \mu \mathrm{g} \mathrm{Cm}^{-2}$, and no EC was detected. All of the data reported have been corrected by the filter blank concentration.

\subsubsection{Source samples}

Diesel exhaust samples were collected on pre-baked quartz filters using a diesel engine (China First Automobile Group Wuxi Diesel Engine Works) which is complied with the emission standard of National Standard in China (Phase III, equivalent to the Euro III emission standard in terms of particulate matter and gaseous pollutant emission levels). The engine was operated with the commercial-available diesel (0\#); the speed and load was controlled by the Schenck DYNAS HT350 dynamometer. There was no size selective inlet present upstream of the quartz filter. Details of the sampling system were reported elsewhere (Zhang et al., 2011). Moreover, biomass smoke samples were collected following the method of Shen et al. (2011). Briefly, a brick cooking stove was built in a kitchen similar to those commonly found in villages in northern China. Two crop residues (wheat and corn) and three types of wood (poplar, pine and elm) were combusted in the stove, and particles in the smokes were collected using quartz filters (without size selective inlet).

\subsection{Sample analysis}

\subsubsection{Thermal-optical analysis}

Quartz filters were analyzed using a DRI Model 2001 thermal/optical carbon analyzer (Atmoslytic Inc., Calabasas, CA) to determine the EC concentration and optical attenuation. The IMPROVE (the Interagency Monitoring and Protective Visual Environmental)-A temperature protocol was implemented in the present study, because it can avoid the loss of native EC in the inert mode as compared with NIOSH (National Institute for Occupational Safety and Health) or similar protocols (Cheng et al., 2010). EC was defined as the carbon evolved after the filter transmittance (monitored at $632 \mathrm{~nm}$ ) returned to its initial value in the oxidizing atmosphere $\left(\mathrm{He} / \mathrm{O}_{2}\right)$. The transmittance charring correction was implemented because the optical attenuation (ATN) is calculated based on the transmittance signal. ATN is defined as:

$\mathrm{ATN}=\ln \left(\frac{I_{0}}{I}\right)$

where $I$ and $I_{0}$ are the transmittance signal before and after the thermal-optical analysis. ATN of blank quartz filters averaged $0.00 \pm 0.01(N=29)$, indicating the ATN of loaded filter could approximately be attributed to the presence of light-absorbing carbon (the mineral dust is far less absorbing, Yang et al., 2009). ATN calculated by Eq. (2) agreed well between duplicate analyses with a slope of $0.99\left(R^{2}=0.984\right.$, $N=28$; intercept was set as zero). The determination of ATN by the carbon analyzer is similar to the Aethalometer, which simultaneously measures light passing through a loaded and a particle-free reference quartz filter. Moreover, the equivalence between ATN retrieved from the carbon analyzer and that measured by the Aethalometer, when the measurement wavelength was the same, has been demonstrated 

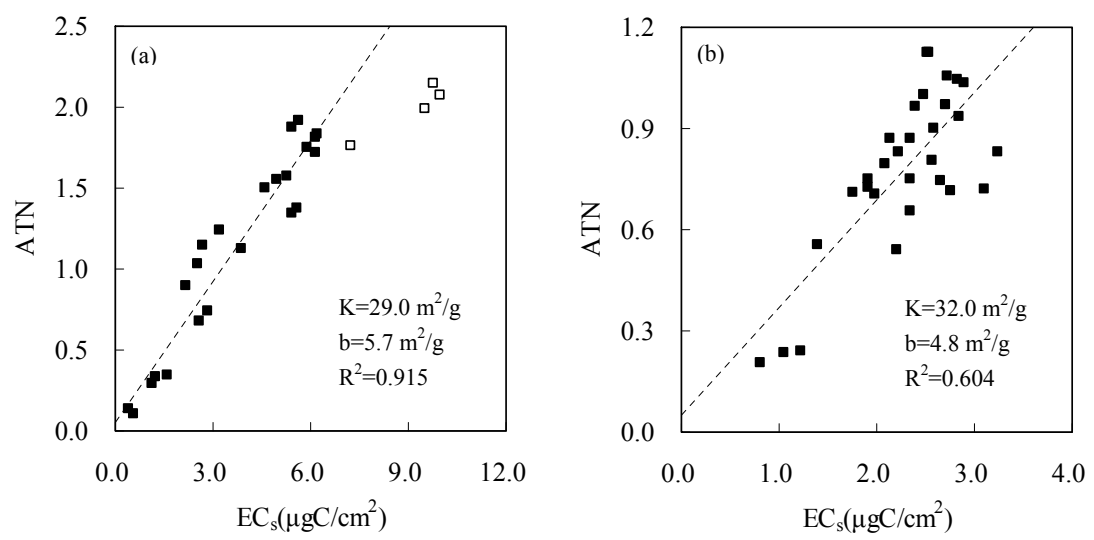

Fig. 1. Dependence of light attenuation measured at $632 \mathrm{~nm}(\mathrm{ATN})$ on the EC loading $\left(\mathrm{EC}_{\mathrm{S}}\right)$ during winter (a) and summer (b) respectively. Linear regression results are shown with $K$ as the slope and $b$ as the intercept. Data points with $\mathrm{EC}_{\mathrm{s}}$ exceeding $7 \mu \mathrm{g} \mathrm{C} \mathrm{cm}^{-2}$, as shown by the open squares, indicated presence of the shadowing effect and were not included when calculating the MAE values.

(Ram and Sarin, 2009). As a result, ATN retrieved from the carbon analyzer can be used to determine the absorption coefficient $\left(b_{\mathrm{abs}}\right)$ of the loaded aerosol by the same approach as used in the Aethalometer, which is calculated as:

$b_{\mathrm{abs}}\left(\mathrm{Mm}^{-1}\right)=\mathrm{ATN} \times \frac{A}{V}$

where $A$ is the filter area with particle loading $\left(\mathrm{mm}^{2}\right)$ and $V$ is the volume of air sampled $\left(\mathrm{m}^{3}\right)$. The mass absorption efficiency (MAE) is then calculated as:

$\operatorname{MAE}\left(\mathrm{m}^{2} / \mathrm{g}\right)=\frac{\mathrm{b}_{\mathrm{abs}}}{\mathrm{EC}}=\frac{\mathrm{ATN} \times \mathrm{A}}{\mathrm{EC} \times \mathrm{V}}=\frac{\mathrm{ATN}}{\mathrm{EC}_{\mathrm{s}}} \times 10^{2}$

where $\mathrm{EC}_{\mathrm{s}}\left(\mu \mathrm{g} \mathrm{Cm}^{-2}\right)$ is the filter loading of EC. Among the artifacts associated with the filter-based measurement of absorption, the multiple scattering effects have been typically corrected by an empirical correction factor, C. Weingartner et al. (2003) suggested a value of $C=3.6$ for the internally mixed aerosol when using Aethalometer. Because the equivalence of optical measurement by the Aethalometer and the carbon analyzer has been demonstrated (Ram and Sarin, 2009), the same empirical factor was used in the present study:

$\operatorname{MAE}_{\text {corrected }}\left(\mathrm{m}^{2} / \mathrm{g}\right)=\frac{\mathrm{MAE}}{3.6}=\frac{\mathrm{ATN}}{\mathrm{EC}_{\mathrm{S}}} \times 10^{2} \times \frac{1}{3.6}$

All the MAE values presented in this study have been corrected for the multiple scattering effects using Eq. (5). Another artifact associated with the filter-based method is the shadowing effect, which could partially be identified by the dependence of ATN on EC loading $\left(\mathrm{EC}_{\mathrm{S}}\right)$. As shown in Fig. 1, during the winter, ATN and $\mathrm{EC}_{\mathrm{S}}$ correlated well $\left(R^{2}=0.915\right)$ with a slope of $29.0 \mathrm{~m}^{2} \mathrm{~g}^{-1}$ and an intercept of $5.7 \mathrm{~m}^{2} \mathrm{~g}^{-1}$ when $\mathrm{EC}_{\mathrm{s}}$ was below $7 \mu \mathrm{g} \mathrm{C} \mathrm{cm}{ }^{-2}$, whereas the linearity did not extend for $\mathrm{EC}_{\mathrm{s}}$ exceeding $7 \mu \mathrm{g} \mathrm{cm}^{-2}$ indicating the presence of shadowing effect. During the summer,
$\mathrm{EC}_{\mathrm{S}}$ was much lower (below $4 \mu \mathrm{g} \mathrm{cm}^{-2}$ ), and the shadowing effect was not identified. As a result, winter samples with $\mathrm{EC}_{\mathrm{S}}$ exceeding $7 \mu \mathrm{g} \mathrm{C} \mathrm{cm}^{-2}$ were not included when calculating the MAE values by Eqs. (2) to (5).

\subsubsection{Water-soluble organic carbon and brown carbon analysis}

Each Teflon filter was placed in a pre-cleaned $60 \mathrm{ml}$ amber HDPE (High-density Polyethylene) bottle and extracted with $40 \mathrm{ml}$ of $18-\mathrm{M} \Omega$ Milli-Q water via $30 \mathrm{~min}$ sonication. The liquid extract was then filtered using a $0.45 \mu \mathrm{m}$ syringe filter and then stored in a refrigerator $\left(\sim 4^{\circ}\right)$ until analysis, which was completed within 2 days after extraction. Water-soluble organic carbon (WSOC) in the extract was quantified using a Sievers Model 900 Total Organic Carbon Analyzer (GE Analytical Instruments, Boulder, $\mathrm{CO}$ ).

The light absorption spectra of the liquid extracts were measured over the wavelength range of 250 to $800 \mathrm{~nm}$ with a UV-Visible Spectrophotometer and Long-Path Absorption Cell, following the method of Hecobian et al. (2010). Water extracts were injected into a 1-m path-length Liquid Waveguide Capillary Cell (LWCC-2100, World Precision Instrument, Sarasota, FL) with an internal volume of $250 \mu \mathrm{L}$. A dual deuterium and tungsten halogen light source (DT-Mini2, Ocean Optics, Dunedin, FL) and absorption spectrometer (USB4000, Ocean Optics, Dunedin, FL) were coupled to the wave-guide via fiber optic cables (QP400-2-SR, Ocean Optics, Dunedin, FL). The absorption spectra were recorded with an Ocean Optics Spectra-Suite data acquisition system.

Light absorption of the liquid extracts is defined as:

$\operatorname{ATN}_{\lambda}=-\log _{10}\left(\frac{\mathrm{I}}{\mathrm{I}_{0}}\right)=\mathrm{L} \times \sum_{i}\left(C_{i} \times \varepsilon_{i, \lambda}\right)$

where $\mathrm{I}_{0}$ and $\mathrm{I}$ are the intensity of incident and transmitted light respectively. $\operatorname{ATN}_{\lambda}$ is linearly dependent on 
the concentration of light-absorbing substances in solution $\left(C_{i}\right)$, their wavelength-dependent mass absorption efficiency $\left(\varepsilon_{i, \lambda}\right)$, and the absorbing path length (L). $\operatorname{ATN}_{\lambda}$ is then converted to the absorption coefficient $\left(b_{\mathrm{abs}}\right)_{\lambda}$ by:

$\left(b_{\mathrm{abs}}\right)_{\lambda}=\left(\mathrm{ATN}_{\lambda}-\mathrm{ATN}_{700}\right) \times \frac{V_{\mathrm{W}}}{\mathrm{V} \times \mathrm{L}} \times \ln (10)$

where $V_{\mathrm{W}}$ is the volume of water into which the filter was extracted $(40 \mathrm{ml}), V$ is the volume of air sampled, and $\mathrm{L}$ is the absorbing path length $(0.94 \mathrm{~m})$. Absorbance at $700 \mathrm{~nm}$ (average between 695 and $705 \mathrm{~nm}$, where there is no absorption for ambient aerosol water extracts) is used to account for baseline drift during analysis. Ln (10) converts from common logarithm (base 10) to natural logarithm. The mass absorption efficiency $\left(\mathrm{MAE}_{\lambda}\right)$ of the water extracts is calculated as:

$\operatorname{MAE}_{\lambda}=\frac{\left(b_{\mathrm{abs}}\right)_{\lambda}}{\mathrm{WSOC}}$

\section{Results and discussion}

\subsection{Optical properties of elemental carbon}

\subsubsection{MAE values of EC in Beijing}

The MAE of EC calculated at $632 \mathrm{~nm}$ by Eqs. (2) to (5) was $8.45 \pm 1.71$ and $9.41 \pm 1.92 \mathrm{~m}^{2} \mathrm{~g}^{-1}$ during winter and summer respectively. The MAE values exhibited significant daily variations, differing by a factor of up to 2.3. Moreover, the daily pattern of MAE seemed to coincide with the OC abundance, especially the $\mathrm{OC}$ to $\mathrm{EC}$ ratio (Fig. $2 \mathrm{a}$ and b). $\mathrm{OC}$ to EC ratios include important information about the extent of secondary organic aerosol (SOA) production such that ambient $\mathrm{OC}$ to $\mathrm{EC}$ ratios greater than those characteristic of the primary emissions for a given area have long been used as an indicator for the SOA formation, giving rise to the EC-tracer method (Turpin and Huntzicker, 1995; Lim and Turpin, 2002). Using this approach, Cheng et al. (2011) predicted the SOC (secondary organic carbon) and POC (primary organic carbon) concentrations of Beijing based on the same sets of samples as used in this study. As shown in Fig. 2c and d, the daily pattern of MAE also coincided well with that of the SOC to OC ratio, whereas no correlation between MAE and the POC to OC ratio was seen. The agreement between the daily pattern of MAE and the OC to EC ratio perhaps indicates the enhancement of MAE by coating with organic aerosol (especially SOA). Another possible explanation for the agreement is the artifacts resulting from the redistribution of liquid-like organic particles (Subramanian et al., 2007; Cappa et al., 2008b) during the filter-based absorption measurements (Lack et al., 2008), which include (i) a physical change in the shape of the liquid-like organic particles as they deposit and then coat the filter fibers, and (ii) the possible coating of pre-existing absorbing particles with the
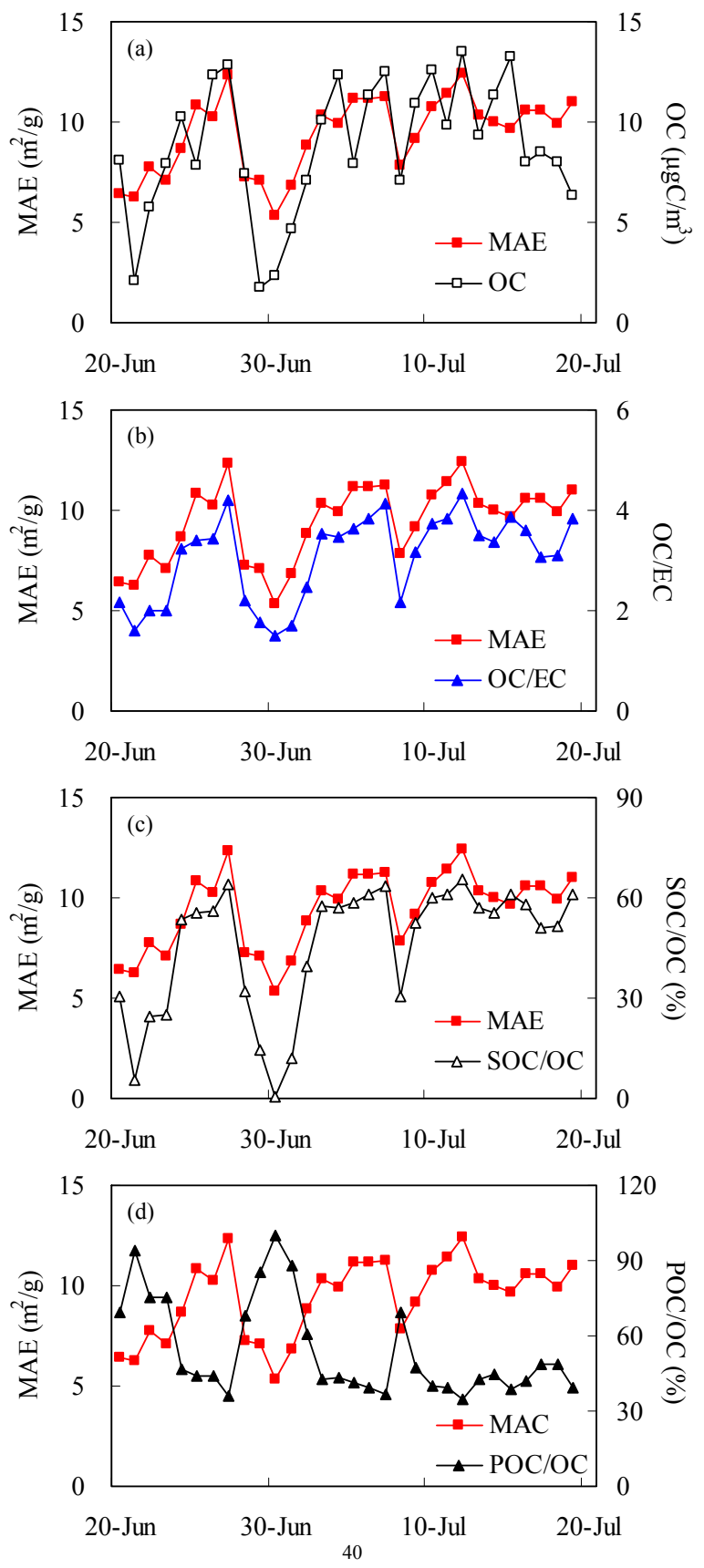

Fig. 2. Daily variation of MAE in Beijing during summer. The daily pattern of OC concentration (a), OC to EC ratio (b), percentage of SOC in OC (c), and percentage of POC in OC (d) are also shown for comparison.

liquid-like organic particles (presumably oxidized) during sampling. We stop further discussion because neither PAS (which can avoid the artifacts associated with filter-based absorption measurement) nor the thermal-denuder (which can be used to investigate the influence of coating) was included in the present study. 
Table 1. Previously published mass absorption efficiency (MAE, in $\mathrm{m}^{2} \mathrm{~g}^{-1}$ ) of elemental carbon (EC). The lower and upper estimates of the equivalent-MAE, which is the estimated value if using the same measurement methods as used in this study, are also shown. See Supplement for the detailed converting process.

\begin{tabular}{|c|c|c|c|c|c|c|c|}
\hline \multirow[t]{2}{*}{ Sampling site } & \multirow[t]{2}{*}{ Sample description } & \multirow[t]{2}{*}{ Methods of $b_{\mathrm{abs}}^{\mathrm{a}}$} & \multirow[t]{2}{*}{ Methods of EC } & \multirow[t]{2}{*}{ Reported $\mathrm{MAE}^{\mathrm{b}}$} & \multicolumn{2}{|c|}{ Equivalent-MAE ${ }^{\mathrm{b}}$} & \multirow[t]{2}{*}{ Reference } \\
\hline & & & & & Lower & Upper & \\
\hline \multicolumn{8}{|l|}{ Group $1^{\mathrm{c}}$} \\
\hline Philadelphia, PA & Severe sulfate haze episodes & Aethalometer $(880 \mathrm{~nm})$ & $\mathrm{NIOSH}(\mathrm{TOT})^{\mathrm{e}}$ & 16.6 & 15.4 & 19.3 & Jeong et al. (2004) \\
\hline Riverside, CA & Urban, summer & Aethalometer $(880 \mathrm{~nm})$ & IMPROVE (TOR) $)^{\mathrm{f}}$ & 4.4 & 7.9 & 11.0 & Babich et al. (2000) \\
\hline New York & Urban, April to September & Aethalometer $(880 \mathrm{~nm})$ & NIOSH (TOT) & 9.2 & 8.6 & 10.7 & Rattigan et al. (2010) \\
\hline Chicago, IL & Urban, autumn & Aethalometer $(880 \mathrm{~nm})$ & IMPROVE (TOR) & 4.0 & 7.3 & 10.1 & Babich et al. (2000) \\
\hline Phoenix, AZ & Urban, winter & Aethalometer $(880 \mathrm{~nm})$ & IMPROVE (TOR) & 3.8 & 6.8 & 9.4 & Babich et al. (2000) \\
\hline Bakersfield, CA & Urban, winter & Aethalometer $(880 \mathrm{~nm})$ & IMPROVE (TOR) & 3.3 & 6.0 & 8.3 & Babich et al. (2000) \\
\hline Dallas, TX & Urban, winter & Aethalometer $(880 \mathrm{~nm})$ & IMPROVE (TOR) & 3.3 & 5.9 & 8.2 & Babich et al. (2000) \\
\hline Philadelphia, PA & Urban, summer & Aethalometer $(880 \mathrm{~nm})$ & IMPROVE (TOR) & 3.3 & 5.9 & 8.2 & Babich et al. (2000) \\
\hline Uniontown, PA & Sub-urban, summer & Aethalometer $(530 \mathrm{~nm})$ & IMPROVE (TOR) & 5.0 & 5.5 & 7.6 & Allen et al. (1999) \\
\hline New York & Urban, October to March & Aethalometer $(880 \mathrm{~nm})$ & NIOSH (TOT) & 6.4 & 6.0 & 7.5 & Rattigan et al. (2010) \\
\hline Evans, Canada & Urban, winter & Aethalometer $(880 \mathrm{~nm})$ & MSC (TOT) ${ }^{\mathrm{g}}$ & 2.6 & 5.2 & 7.2 & Sharma et al. (2002) \\
\hline Scotland, UK & Rural, June to December & Aethalometer $(880 \mathrm{~nm})$ & NIOSH (TOT) & 6.1 & 5.7 & 7.1 & Quincey et al. (2009) \\
\hline Atlanta, GA & Urban, summer & Aethalometer $(880 \mathrm{~nm})$ & NIOSH (TOT) & 5.7 & 5.3 & 6.6 & Lim et al. (2003) \\
\hline Toronto, Canada & Urban, annual & Aethalometer $(880 \mathrm{~nm})$ & NIOSH (TOT) & 5.5 & 5.1 & 6.4 & Knox et al. (2009) \\
\hline Durham, NC & Urban, summer & Aethalometer $(880 \mathrm{~nm})$ & NIOSH (TOT) & 5.4 & 5.0 & 6.3 & Rice (2004) \\
\hline Egbert, Canada & Rural, summer & Aethalometer $(880 \mathrm{~nm})$ & IMPROVE (TOR) & 2.4 & 4.4 & 6.1 & Sharma et al. (2002) \\
\hline Riverside, CA & Urban, summer & Aethalometer $(880 \mathrm{~nm})$ & NIOSH (TOT) & 5.1 & 4.8 & 6.0 & Snyder and Schauer (2007) \\
\hline Palmerston, Canada & Urban, summer & Aethalometer $(880 \mathrm{~nm})$ & MSC (TOT) & 2.1 & 4.1 & 5.7 & Sharma et al. (2002) \\
\hline \multicolumn{8}{|l|}{ Group 2} \\
\hline Beijing, China & Urban, summer & DRI analyzer (632 nm) & IMPROVE-A (TOT) ${ }^{\mathrm{h}}$ & 9.4 & & & This study \\
\hline Beijing, China & Urban, winter & DRI analyzer $(632 \mathrm{~nm})$ & IMPROVE-A (TOT) & 8.5 & & & This study \\
\hline Lahore, Pakistan ${ }^{\mathrm{d}}$ & Urban, winter & Aethalometer $(880 \mathrm{~nm})$ & NIOSH $(\mathrm{TOT})^{\mathrm{i}}$ & 5.8 & n.a. & 7.5 & Husain et al. (2007) \\
\hline Lycksele, Sweden ${ }^{\mathrm{d}}$ & Urban, wood burning season & Aethalometer (880nm) & NIOSH (TOT) & 3.7 & 4.8 & 6.0 & Krecl et al. (2007) \\
\hline Manora Peak, India ${ }^{d}$ & High altitude, winter & Sunset analyzer (678nm) & NIOSH (TOT) ${ }^{\mathrm{i}}$ & 6.9 & n.a. & 5.3 & Ram and Sarin (2009) \\
\hline Mt. Abu, India ${ }^{\mathrm{d}}$ & High altitude, winter & Sunset analyzer (678nm) & NIOSH $(\mathrm{TOT})^{i}$ & 4.6 & n.a. & 3.5 & Ram and Sarin (2009) \\
\hline Hisar, India ${ }^{\mathrm{d}}$ & Urban, winter & Sunset analyzer $(678 \mathrm{~nm})$ & NIOSH (TOT) ${ }^{\mathrm{i}}$ & 3.6 & n.a. & 2.7 & Ram and Sarin (2009) \\
\hline Allahabad, India ${ }^{\mathrm{d}}$ & Urban, winter & Sunset analyzer $(678 \mathrm{~nm})$ & NIOSH (TOT) ${ }^{\mathrm{i}}$ & 3.1 & n.a. & 2.4 & Ram and Sarin (2009) \\
\hline Philadelphia, $\mathrm{PA}^{\mathrm{d}}$ & Canadian forest fire event & Aethalometer $(880 \mathrm{~nm})$ & NIOSH (TOT) & 1.6 & 2.1 & 2.6 & Jeong et al. (2004) \\
\hline
\end{tabular}

a The operating-wavelength shown in parentheses, which is the value of $\lambda$ in Eq. (11);

b MAC values corrected by the multiple scattering effects using an empirical correction factor of $C=3.6$;

c $A=1$ in Eq. (11);

d $A=2$ in Eq. (11);

e NIOSH temperature protocol with transmittance correction. In Equation $(11), f_{\text {charring }}=1, f_{\text {protocol }}=1.2 \sim 1.5$;

${ }^{\mathrm{f}}$ IMPROVE temperature protocol with reflectance correction. In Equation $(11), f_{\text {charring }}=1.3 \sim 1.8, f_{\text {protocol }}=1$;

g MSC (Meteorological Service of Canada) temperature protocol with transmittance correction. EC determined by the MSC method was 1.09 times the value of that determined by the IMPROVE temperature protocol with reflectance correction (Sharma et al., 2002). In Equation (10), $f_{\text {charring }}=(1.3 \sim 1.8) \times 1.09, f_{\text {protocol }}=1$;

$\mathrm{h}$ IMPROVE-A temperature protocol with transmittance correction.

${ }^{\mathrm{i}}$ In Eq. (11), $f_{\text {charring }}=1, f_{\text {protocol }} \geq 1.5$. As a result, only the upper estimate of equivalent-MAE is available.

\subsubsection{Effects of the measurement methods}

Previous studies have quantified the MAE by the filter-based method at a variety of locations (Table 1). However, quite different measurement methods of both $\mathrm{ATN}$ and $\mathrm{EC}_{\mathrm{s}}$ have been implemented, introducing complexity and difficulty in the direct comparison of MAE across studies and regions. As a result, an approach was developed to account for the discrepancy caused by measurements methods of both ATN and $\mathrm{EC}_{\mathrm{s}}$. Based on this approach, previously reported MAE values were converted to the equivalent-MAE, which is the estimated value if using the same measurement methods (of both ATN and $\mathrm{EC}_{\mathrm{S}}$ ) as used in this study. This was done using the following procedures.

(1) EC method conversion. The thermal-optical method is widely used for the determination of EC. A variety of op- erational protocols have been employed that differ mainly with respect to (i) temperature protocol, including temperature plateaus and residence time at each plateaus, and (ii) charring correction by light reflectance or transmittance. EC values defined by transmittance correction $\left(\mathrm{EC}_{\mathrm{T}}\right)$ are usually lower than those defined by reflectance correction $\left(\mathrm{EC}_{\mathrm{R}}\right)$, because the filter reflectance signal typically returns to its initial value before the transmittance (Chow et al., 2004). Influence of the charring correction methods on EC values is shown in Table 2. When using the IMPROVE or the IMPROVEA temperature protocol, the $\mathrm{EC}_{\mathrm{R}}$ to $\mathrm{EC}_{\mathrm{T}}$ ratio was about $1.3 \sim 1.8$ for ambient samples whereas the ratio was a little lower (about 1.2) for motor vehicle exhaust samples. As a result, when converting MAE values in which EC was determined by the IMPROVE (or IMPROVE-A) temperature protocol with reflectance correction, the reported MAE was 
Table 2. Ratios of reflectance-defined EC $\left(\mathrm{EC}_{\mathrm{R}}\right)$ to transmittance-defined $\mathrm{EC}\left(\mathrm{EC}_{\mathrm{T}}\right)$.

\begin{tabular}{lllll}
\hline Protocol & Sampling site & Sample description & Ratio & Reference \\
\hline IMPROVE & Multiple, US & Urban, sub-urban, and rural & 1.78 & Chow et al. (2001) \\
IMPROVE & Multiple, Mexico & Urban & 1.47 & Chow et al. (2001) \\
IMPROVE & Fresno, CA & Aug 2002-Apr 2003; urban & 1.49 & Chow et al. (2004) \\
IMPROVE & Fresno, CA & Aug-Sep 2005; urban & 1.33 & Chow et al. (2009) \\
IMPROVE-A & Beijing, China & Winter and summer, 2009; urban & 1.78 & Cheng et al. (2010) \\
IMPROVE & - & Motor vehicle exhaust; source & 1.21 & Chow et al. (2001) \\
\hline
\end{tabular}

multiplied by $1.3 \sim 1.8$ to account for the discrepancy caused by charring correction methods.

Measured EC values have also been shown to vary significantly among the various temperature protocols (Schauer et al., 2003; Subramanian et al., 2006; Cheng et al., 2010). Based on results from North America and Europe, ambient EC defined by the IMPROVE temperature protocol

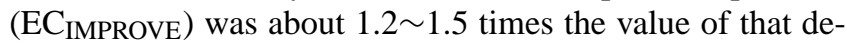
fined by NIOSH ( $\left.\mathrm{EC}_{\mathrm{NIOSH}}\right)$ when both using the transmittance correction (Cheng et al., 2010 and references therein). Few studies about the $\mathrm{EC}_{\mathrm{IMPROVE}}$ to $\mathrm{EC}_{\mathrm{NIOSH}}$ ratio were available for Asia and quite different results have been reported. Results from Schauer et al. (2003) suggested that the ratio was about 1.5 for a regional background site in Korea whereas recent work by Cheng et al. (2010) indicated that the ratio may be greater than 2.0 for Beijing, China. Importantly, the discrepancy between EC values determined by different methods was suggested to be strongly linked to brown carbon such that the discrepancy was larger when the contribution of brown carbon was high (Reisinger et al., 2008). The $\mathrm{EC}_{\text {IMPROVE }}$ to $\mathrm{EC}_{\mathrm{NIOSH}}$ ratio for Asia is expected to be higher than that for North America and Europe, due to the much stronger emissions from the biomass burning and residential coal combustion (Bond et al., 2004; Venkataraman et al., 2005; Gustafsson et al., 2009) which are known to emit large amounts of brown carbon. When converting the MAE values in which EC was determined by the NIOSH temperature protocol with transmittance correction, different converting factors were used to account for the discrepancy caused by the temperature protocol: if the reported MAE was measured in North America or Europe, it was divided by $1.2 \sim 1.5$; if the reported MAE was measured in Asia, it was divided by 1.5 to obtain upper estimate of the equivalence MAE. Moreover, it should be pointed out that the EC IMPROVE $_{\text {IMP }}$ to $\mathrm{EC}_{\mathrm{NIOSH}}$ ratio for North America and Europe $(1.2 \sim 1.5)$ has included results from the heating (wood burning) season when the influence of biomass burning is expected to be more significant.

(2) Wavelength measurement correction. As discussed in Sect. 2.2.1, it is acceptable to assume that ATN quantified by the carbon analyzer and that calculated by the Aethalometer differ only in the measurement wavelength (Ram and Sarin, 2009). As a result, when converting the MAE values in which ATN was determined by Aethalometer, only the wavelength $(\lambda)$ dependence of MAE was considered, which can be represented as a power-law relationship using an Ångström exponent $(\mathrm{A})$ :

$\operatorname{MAE}_{\lambda}=K \times \lambda^{-A}$

where $K$ is a constant that includes the aerosol mass concentration. Then the MAE measured at a given wavelength $\left(\mathrm{MAE}_{\lambda}\right)$ could be converted to that measured at $632 \mathrm{~nm}$ (MAE 632 ) by Eq. (10):

$\operatorname{MAE}_{632}=\operatorname{MAE}_{\lambda} \times\left(\frac{\lambda}{632}\right)^{A}$

Kirchstetter et al. (2004) found that light absorption by the motor vehicle aerosols (roadway and tunnel samples) exhibited relatively weak wavelength dependence such that absorption varied approximately as $\lambda^{-1}$, whereas the biomass smoke aerosols (produced by wood and savanna burning) had much stronger wavelength dependence, approximately $\lambda^{-2}$. Schnaiter et al. (2003) also suggested a value of 1.056 for the Ångström exponent of diesel soot. Comparably, results quantified by the electron energy-loss spectrum in the transmission electron microscope showed that the Ångström exponent of ambient soot and "tar balls" (a typical type of brown carbon) was about 1 and 1.5 respectively (Alexander et al., 2008). When performing the wavelength correction by Eq. (10), a value of Ångström exponent $=2$ was used if the reported MAE was measured during the period or in the region that impacted by biomass burning; in other cases, we assumed the Ångström exponent was 1.

(3) The whole converting approach. After incorporating the EC method conversion and the wavelength measurement correction, the whole converting approach to calculate the equivalent-MAE from reported values is:

equivalent-MAE $=\operatorname{MAE}_{\lambda} \times \frac{f_{\text {charring }}}{f_{\text {protocol }}} \times\left(\frac{\lambda}{632}\right)^{A}$

$f_{\text {charring }}$ is the converting factor of charring correction method. $f_{\text {charring }}=1.3 \sim 1.8$ for the reported MAE in which EC was determined by the IMPROVE (or IMPROVE-A) temperature protocol with reflectance correction. $f_{\text {protocol }}$ 
is the converting factor of temperature protocol. With respect to the reported MAE in which EC was determined by the NIOSH temperature protocol with transmittance correction, $f_{\text {protocol }}=1.2 \sim 1.5$ if the reported MAE was measured in North America or Europe (including that measured during the heating or wood burning season), whereas $f_{\text {protocol }} \geq 1.5$ if the reported MAE was measured in Asia. $\lambda$ is the wavelength at which the reported MAE is measured. $A$ is the Angström exponent. $A=2$ if the reported MAE was measured during the period or in the region that impacted by biomass burning; in other cases, it is assumed that $A=1$. Moreover, with respect to the absorption measurement, only the wavelength dependence was considered in the current converting approach (Eq. 11); as a result, the approach was only used to convert the reported MAE values based on Aethalometer or carbon analyzer (Table 1).

Effects of the converting approach on the reported MAE values depend on the measurement methods of both light absorption and EC concentration. As shown in Table 1, if the reported MAE were calculated by ATN measured at a wavelength greater than $632 \mathrm{~nm}($ e.g., $880 \mathrm{~nm})$ together with EC defined by the IMPROVE temperature protocol with reflectance correction, the equivalent-MAE would be substantially higher than the reported value, because the reported MAE would be increased by both the EC method conversion and the wavelength measurement correction process. For example, it seems that MAE values obtained in this study were about $1 \sim 2$ times higher than those reported by Babich et al. (2000); but the converting approach increased the reported MAE values by a factor of 1.8 2.5, indicating the MAE values reported by Babich et al. (2000) were in fact comparable with results from this study. With respect to the reported MAE values which were quantified by ATN measured at $880 \mathrm{~nm}$ together with EC defined by the NIOSH temperature protocol with transmittance correction, the converting approach would increase the reported MAE values by a factor of $1.3 \sim 1.6$ if the contribution of biomass burning is important (e.g., Krecl et al., 2007); in other cases, the converting approach has little influence on the reported MAE values (e.g., Rattigan et al., 2010).

\subsubsection{Effects of biomass burning and brown carbon}

Other factors in addition to measurement methods that influence MAE values can be investigated based on the converting approach described above, which would provide deep insight into the optical properties of elemental (or black) carbon. Before further discussion, the equivalent-MAE values shown in Table 1 were classified into two groups. The first group includes most of the results from North America and Europe, whereas the second one comprises results from Asia and those measured in North America and Europe during the periods impacted by biomass burning. As shown in Fig. 3, the average equivalent-MAE of the first group was above $4 \mathrm{~m}^{2} \mathrm{~g}^{-1}$ and was most frequently found in
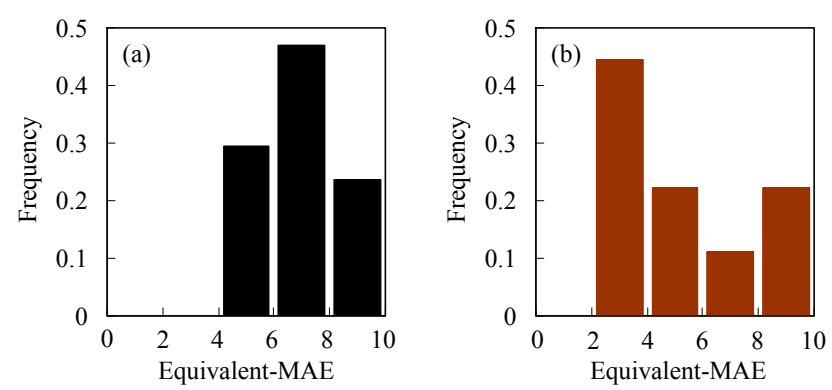

Fig. 3. Frequency distribution of the average equivalent-MAE for Group 1 (a) and Group 2 (b) shown in Table 1. The extremely high value $\left(17.4 \mathrm{~m}^{2} \mathrm{~g}^{-1}\right)$ measured in Philadelphia, PA during severe sulphate haze episodes occurred in the summer of 2002 was not included in (a). Upper estimate is used as the average value if the lower estimate is not available (e.g. Hisar, India).

the range of $6 \sim 8 \mathrm{~m}^{2} \mathrm{~g}^{-1}$. Comparing with the first group, the most noticeable feature of the second group was that quite a few equivalent-MAE values were below $4 \mathrm{~m}^{2} \mathrm{~g}^{-1}$. For example, extremely low equivalent-MAE values, which were below $2.7 \mathrm{~m}^{2} \mathrm{~g}^{-1}$, were found in two Indian cities (Hisar and Allahabad). EC in India has been shown to be dominated by emissions from biomass burning (Bond et al., 2004; Venkataraman et al., 2005; Gustafsson et al., 2009), which is known to emit a significant amount of brown carbon that can not be directly measured by the currently-used thermaloptical equipments. Wonaschütz et al. (2009) introduced an optical method, which relies on calibration curves of carbon black (a standard for soot) and humic acid sodium salt (a proxy for brown carbon), to separate brown carbon from soot according to their different wavelength dependence of light absorption characteristics. Based on this approach, Reisinger et al. (2008) and Wonaschütz et al. (2009) found that thermal and thermal-optical method overestimated EC concentration when the contribution of brown carbon was important, indicating a considerable fraction of brown carbon can be classified as EC. On the other hand, brown carbon is less absorbing comparing with native EC. For example, the MAE of "tar balls" (a typical type of brown carbon) and soot was found to be $3.6 \sim 4.1$ and $4.3 \sim 4.8 \mathrm{~m}^{2} \mathrm{~g}^{-1}$ at $550 \mathrm{~nm}$, respectively (Alexander et al., 2008); whereas much lower MAE values (below $1 \mathrm{~m}^{2} \mathrm{~g}^{-1}$ at $532 \mathrm{~nm}$ ) were suggested for the whole brown carbon (Favez et al., 2009; Flowers et al., 2010). As a result, brown carbon (or emissions from biomass burning) is expected to decrease the value of MAE, indicating that the large amount of brown carbon in the atmosphere of India, which is emitted from biomass burning, is the most likely factor leading to its significantly lower MAE values compared with other regions. The hypothesis was further supported by results from North America. For example, the average equivalent-MAE of Philadelphia, PA was only $2.4 \mathrm{~m}^{2} \mathrm{~g}^{-1}$ when heavily impacted by biomass burning (Jeong et al., 2004), significantly lower than the result 


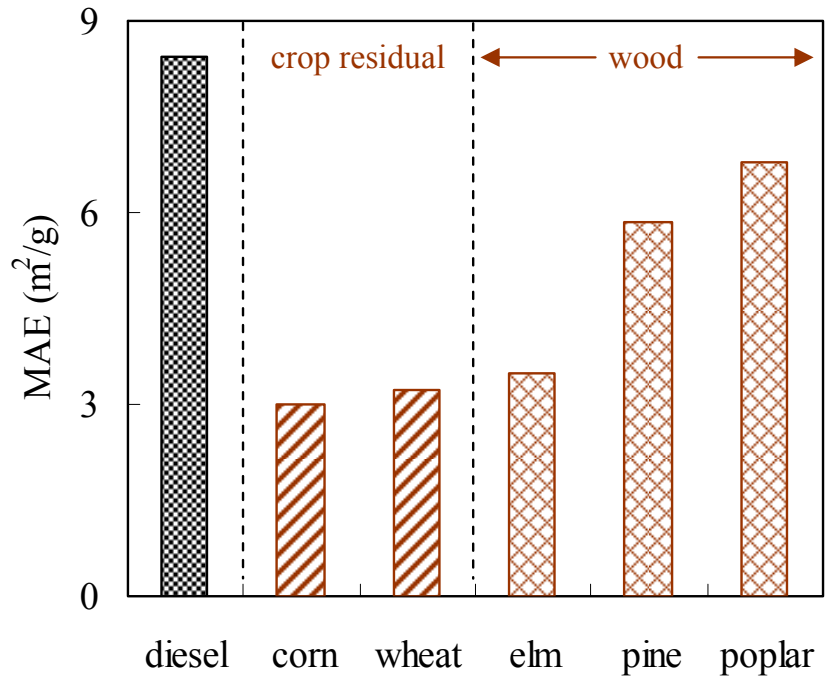

Fig. 4. MAE of diesel exhaust and biomass smoke samples.

$\left(7.1 \mathrm{~m}^{2} \mathrm{~g}^{-1}\right)$ when the influence of biomass burning was not important (Babich et al., 2000).

Results from source samples can provide addition insight into the effects of biomass burning. The MAE of biomass smoke samples was $3.0 \sim 3.2$ and $3.6 \sim 6.8 \mathrm{~m}^{2} \mathrm{~g}^{-1}$ for crop residues (wheat and corn) and wood (poplar, pine and elm) respectively whereas much higher value $\left(8.4 \mathrm{~m}^{2} \mathrm{~g}^{-1}\right)$ was observed for diesel exhaust (Fig. 4), providing solid evidence for the hypothesis that emissions from biomass burning would decrease the MAE of EC.

\subsection{Optical properties of water-soluble organic carbon}

WSOC averaged 7.3 and $3.4 \mu \mathrm{gC} \mathrm{m}^{-3}$, and constituted $22 \%$ and $39 \%$ of OC (measured by the denuded quartz filter), during winter and summer respectively (Cheng et al., 2011). The light absorption spectra over the wavelength range of 250 to $800 \mathrm{~nm}$ were recorded for the liquid extracts. The power law fit well in the wavelength range of $330-480 \mathrm{~nm}$ as shown in Fig. 5. The Ångstrom exponents calculated by Eq. (9) averaged $7.5 \pm 0.9$ and $7.0 \pm 0.8$ during winter and summer respectively. The Ångstrom exponents were similar to those of HULIS isolated from the ambient aerosol in Amazonian biomass burning plumes (Hoffer et al., 2006), and are also comparable with those of the water extracts measured in the southeastern United States (Hecobian et al., 2010). The absorption spectra observed for the WSOC (Fig. 5) is characteristic of the brown carbon spectra with a sharply increasing absorption when wavelength decreases (ATN $\sim \lambda^{-7}$ ), which strongly supports that WSOC (or a fraction of WSOC) obtained in this study is brown carbon. In fact, a significant quantity of evidence for the atmospheric presence of brown carbon comes from the spectral properties of water extracts of continental aerosol (Andreae and Gelencsér, 2006; Lukács et al., 2007). Recently, a fraction of brown carbon was found

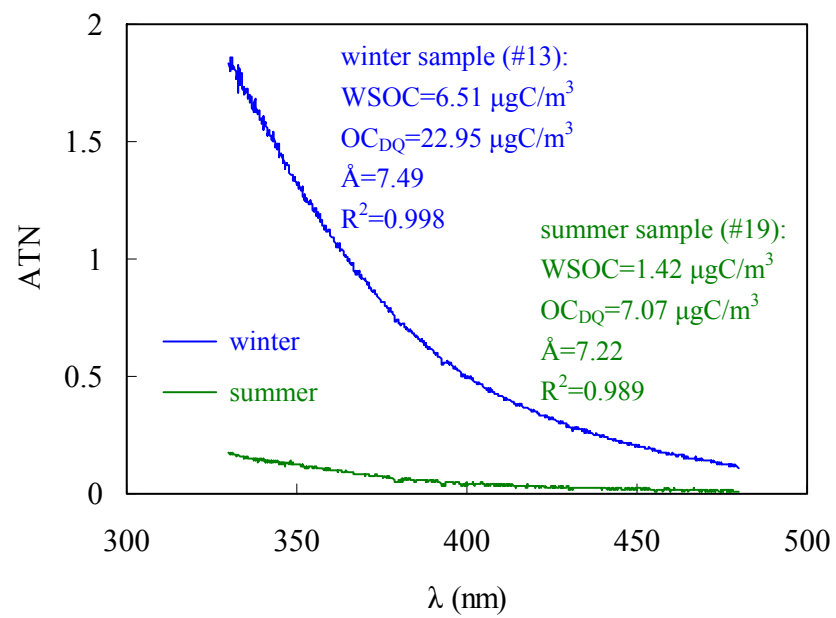

Fig. 5. Representative adsorption spectra of WSOC during winter and summer respectively.

to be non-water-soluble (Chen and Bond, 2010), but this fraction was not the focus of this study.

Though the light absorption spectra were recorded from 250 to $800 \mathrm{~nm}$, the absorption coefficient $\left(b_{a b s}\right)$ and mass absorption efficiency (MAE) of WSOC were calculated at $365 \mathrm{~nm}$ (average between 360 and 370nm) by Eqs. (6) to (8). This wavelength was chosen to avoid interferences from non-organic compounds such as nitrate and to maintain consistency with previously published results (Lukács et al., 2007; Hecobian et al., 2010). The MAE of WSOC averaged $1.79 \pm 0.24$ and $0.71 \pm 0.20 \mathrm{~m}^{2} \mathrm{~g}^{-1}$ during winter and summer respectively. Moreover, $b_{\mathrm{abs}}$ and WSOC correlated well with a slope of $1.83 \pm 0.03 \mathrm{~m}^{2} \mathrm{~g}^{-1}\left(R^{2}=0.977\right)$ during winter, whereas the regression between $b_{a b s}$ and WSOC showed a slope of $0.70 \pm 0.03 \mathrm{~m}^{2} \mathrm{~g}^{-1}$ in summer $\left(R^{2}=0.734\right.$, Fig. 6). Cheng et al. (2011) found that WSOC correlated strongly $\left(R^{2}=0.84 \sim 0.94\right)$ with the secondary organic aerosol (SOA) predicted by the EC-tracer method, indicating a substantial fraction of WSOC is SOA in Beijing; moreover, the estimated SOA accounted for about 40 and $50 \%$ of organic aerosol (OA, measured by the denuded quartz filter) during winter and summer respectively, suggesting considerable SOA production despite the low temperature and relative humidity in winter. Importantly, the emission of biogenic volatile organic compounds (BVOCs) in Beijing showed a distinct seasonal pattern such that the BVOCs emission reached a maximum in summer (e.g., $4.4 \times 10^{9} \mathrm{gC}$ in July) whereas the emission was about 1000 times lower during winter (e.g., $6.3 \times 10^{6} \mathrm{gC}$ in January, Wang et al., 2003). As a result, anthropogenic volatile organic compounds (AVOCs) should be more important as the precursors of SOA during winter compared with summer. Given the fact that WSOC is strongly linked to SOA in Beijing, the difference in the precursors of SOA is the most likely cause of the large discrepancy between the MAE of WSOC during winter and summer. 


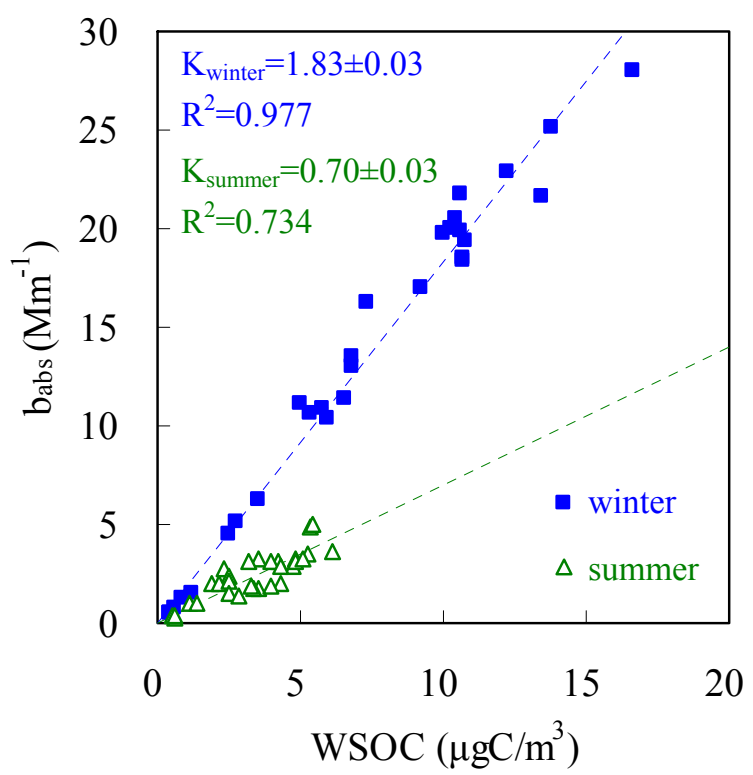

Fig. 6. Dependence of $b_{\mathrm{abs}}$ measured at $365 \mathrm{~nm}$ on the WSOC concentration during winter and summer. Linear regression results are shown with $K$ as the slope (intercept is set as zero).

Previous studies suggested that biomass burning is another source of WSOC (Sullivan et al., 2006; Weber et al., 2007; Snyder et al., 2009). Effects of biomass burning on the MAE of WSOC could be illustrated by results from the southeastern United States. Hecobian et al. (2010) found that the MAE of WSOC (measured at $365 \mathrm{~nm}$ using the same method as used in this study) were $0.31 \pm 0.07 \mathrm{~m}^{2} \mathrm{~g}^{-1}$ for the urban sites of the southeastern United States when the contribution of biomass burning was not important (identified by levoglucosan $<50 \mathrm{ng} \mathrm{m}^{-3}$, typically in the summer), whereas the MAE averaged $0.70 \pm 0.07 \mathrm{~m}^{2} \mathrm{~g}^{-1}$ when the influence of biomass burning was significant (identified by levoglucosan $>50 \mathrm{ng} \mathrm{m}^{-3}$, typically in the winter). On the other hand, Sun et al. (2011) compared the results from High-Resolution Time-of Flight Aerosol Mass Spectrometer (HR-ToF-AMS) and Gas Chromatography-Mass Spectrometry (GC-MS), and found that the mass spectra of WSOC collected in the southeastern United States was characterized by a less oxidized component associated with biogenic SOA and a more oxidized component associated with biomass burning. Moreover, the less oxidized component accounted for $75 \%$ of WSOC in summer while the more oxidized component accounted for $78 \%$ in winter, suggesting that WSOC in the southeastern United States is primarily contributed by SOA in summer and by biomass burning in winter. These results indicate that WSOC emitted from biomass burning is more light-absorbing compared with that formed by atmospheric reaction. Both the ambient concentration of levoglucosan (the levoglucosan concentration was above $100 \mathrm{ng} \mathrm{m}^{-3}$ all year round in Beijing; Zhang et al., 2008) and emission inventory (Bond et al., 2004) demonstrated that biomass burning emission is much stronger in China compared with America, which is a likely cause of the much higher MAE value in Beijing $\left(0.70 \sim 1.83 \mathrm{~m}^{2} \mathrm{~g}^{-1}\right)$ compared with the southeastern United States $\left(0.31 \sim 0.70 \mathrm{~m}^{2} \mathrm{~g}^{-1}\right)$.

Recent results from source apportionment by CMB (chemical mass balance) suggested that biomass burning accounted for 11 and $26 \%$ of ambient OC in Beijing during summer and winter respectively, which was consistent with the levoglucosan to OC ratio (0.6 and $1.4 \%$ during summer and winter respectively, Wang et al., 2009). Thus, biomass burning may be also responsible for the phenomenon that the MAE of WSOC in Beijing was much higher in winter compared with summer.

\section{Conclusions}

The MAE of EC in Beijing was quantified using a thermaloptical carbon analyzer. The absorption measurement was performed at $632 \mathrm{~nm}$ and the EC concentration was determined by the IMPROVE-A temperature protocol with transmittance charring correction. The MAE was $8.45 \pm 1.71$ and $9.41 \pm 1.92 \mathrm{~m}^{2} \mathrm{~g}^{-1}$ during winter and summer respectively, and the daily variation of MAE was found to coincide with the $\mathrm{OC}$ abundance, especially the OC to EC ratio. A converting approach was developed to account for the discrepancy caused by measurements methods of both light absorption and EC concentration. Based on this approach, previously published MAE values were converted to the equivalentMAE, which is the estimated value if using the same measurement methods as used in this study. The equivalent-MAE values were found to be much lower in the regions heavily impacted by biomass burning. Results from source samples showed that the MAE of biomass smoke samples was significantly lower than diesel exhaust samples, also suggesting that emissions from biomass burning would decrease the MAE of EC.

The absorption spectra of WSOC in Beijing was characteristic of the brown carbon spectra with a sharply increasing absorption when wavelength decreases (ATN $\sim \lambda^{-7}$ ). The MAE of WSOC (measured at $365 \mathrm{~nm}$ ) was $1.79 \pm 0.24$ and $0.71 \pm 0.20 \mathrm{~m}^{2} \mathrm{~g}^{-1}$ during winter and summer respectively; and the seasonal variation was attributed to the difference in the precursors of SOA. Moreover, the MAE of WSOC in Beijing was found to be much higher than results from the southeastern United States which were obtained using the same method as used in this study, perhaps due to the influence of biomass burning.

\section{Implications}

The importance of optical properties of ambient aerosol has been widely recognized in China, due to increasing concerns on visibility, haze, and climate change; however, the optical 
measurements are still very lacking. This study introduces a method that quantifying the MAE of EC by a thermal-optical carbon analyzer, which has the advantage of not requiring an additional instrument to measure the light attenuation. As a result, this method is suitable for China at present, especially when the optical instruments (e.g., Aethalometer and PSAP) are not available. This study also develops an approach that accounts for the influence of measurement methods on the MAE of EC, which is very meaningful for the integration or comparison of MAE values across studies and regions. The converting approach also suggests the benefits and importance of standardized methods for the determination of EC concentration and its optical parameters (e.g., $b_{\mathrm{abs}}$ ). Brown carbon has recently come into the forefront of atmospheric research. One concern that brown carbon contributes to is the potential radiative forcing due to absorption similar to black carbon, as well as interference with black carbon measurement made by absorption-based instruments. Though there has been a lot of evidence for the atmospheric presence of brown carbon (e.g., WSOC, humic-like substances and "tar balls"), more efforts should be made to quantify the total mass concentration of brown carbon.

\section{Supplement related to this article is available online at: http://www.atmos-chem-phys.net/11/11497/2011/ acp-11-11497-2011-supplement.pdf.}

Acknowledgements. This work was supported by the National Natural Science Foundation of China (21107061), the National 973 Program of China (2010CB951803), and the Foundation for the Author of National Excellent Doctoral Dissertation of China (2007B57). We acknowledge visiting scholar Charles N. Freed for revising the paper, and acknowledge James J. Schauer in University of Wisconsin-Madison for his valuable comments. We thank Yun-shan Ge and Jian-wei Tan in Beijing Institute of Technology for their help in the collection of diesel exhaust samples, and thank Shu Tao and Guo-feng Shen in Peking University for their help in the collection of biomass smoke samples. We also thank Chen Lai-guo, Marcus Trail, and Colin Boswell for their help in the analysis.

Edited by: X. Tie

\section{References}

Alexander, D. T. L., Crozier, P. A., and Anderson, J. R.: Brown carbon spheres in East Asian outflow and their optical properties, Science, 321, 833-836, 2008.

Allen, G. A., Lawrence, J., and Koutrakis, P.: Field validation of a semi-continuous method for aerosol black carbon (Aethalometer) and temporal patterns of summertime hourly black carbon measurements in southwestern PA, Atmos. Environ., 33, 817823, 1999.

Andreae, M. O. and Crutzen, P. J.: Atmospheric aerosols: biogeochemical sources and role in atmospheric chemistry, Science, 276, 1052-1058, 1997.
Andreae, M. O. and Gelencsér, A.: Black carbon or brown carbon? The nature of light-absorbing carbonaceous aerosols, Atmos. Chem. Phys., 6, 3131-3148, doi:10.5194/acp-6-3131-2006, 2006.

Arnott, W. P., Moosmüller, H., Sheridan, P. J., Ogren, J. A., Raspet, R., Slaton, W. V., Hand, J. L., Kreidenweis, S. M., and Collett Jr., J. L.: Photoacoustic and filter-based ambient aerosol light absorption measurements: instrument comparisons and the role of relative humidity, J. Geophys. Res., 108, 4034, doi:10.1029/2002JD002165, 2003.

Babich, P., Davey, M., Allen, G., and Koutrakis, P.: Method comparisons for particulate nitrate, elemental carbon, and $\mathrm{PM}_{2.5}$ mass in seven US cities, J. Air Waste Manage. Assoc., 50, 10951105, 2000.

Bergstrom, R. W., Ackerman, T. P., and Richards, L. W.: Optical Properties of particulate elemental carbon. Particulate carbon: atmospheric life cycle, edited by: Wolff, G. T. and Klimisch, R. L., Plenum Press, New York, USA, 43-51, 1982.

Bergstrom, R. W., Pilewskie, P., Russell, P. B., Redemann, J., Bond, T. C., Quinn, P. K., and Sierau, B.: Spectral absorption properties of atmospheric aerosols, Atmos. Chem. Phys., 7, 5937-5943, doi:10.5194/acp-7-5937-2007, 2007.

Birch, M. E. and Cary, R. A.: Elemental carbon-based method for monitoring occupational exposures to particulate diesel exhaust, Aerosol Sci. Technol., 25, 221-241, 1996.

Bond, T. C.: Spectral dependence of visible light absorption by carbonaceous particles emitted from coal combustion, Geophys. Res. Lett., 28, 4075-4078, doi:10.1029/2001GL013652, 2001.

Bond, T. C. and Bergstrom, R. W.: Light absorption by carbonaceous particles: an investigative review, Aerosol Sci. Technol., 40, 27-67, 2006.

Bond, T. C., Habib, G., and Bergstrom, R. W.: Limitations in the enhancement of visible light absorption due to mixing state, J. Geophys. Res., 111, D20211, doi:10.1029/2006JD007315, 2006.

Bond, T. C., Streets, D. G., Yarber, K. F., Nelson, S. M., Woo, J. H., and Klimont, Z.: A technology-based global inventory of black and organic carbon emissions from combustion, J. Geophys. Res., 109, D14203, doi:10.1029/2003JD003697, 2004.

Cappa, C., Lack, D., Burkholder, J., and Ravishankara, A.: Bias in filter-based aerosol light absorption measurements due to organic aerosol loading: evidence from laboratory measurements, Aerosol Sci. Technol., 42, 1022-1033, 2008a.

Cappa, C. D., Lovejoy, E. R., and Ravishankara, A. R.: Evidence for liquid-like and nonideal behavior of a mixture of organic aerosol components, P. Natl. Acad. Sci. USA, 105, 18687-18691, 2008b.

Chakrabarty, R. K., Moosmüller, H., Garro, M. A., Arnott, W. P., Walker, J., Susott, R. A., Babbitt, R. E., Wold, C. E., Lincoln, E. N., and Hao, W. M.: Emissions from the laboratory combustion of wildland fuels: particle morphology and size, J. Geophys. Res., 111, D07204, doi:10.1029/2005JD006659, 2006.

Chakrabarty, R. K., Moosmüller, H., Chen, L. W. A., Lewis, K., Arnott, W. P., Mazzoleni, C., Dubey, M. K., Wold, C. E., Hao, W. M., and Kreidenweis, S. M.: Brown carbon in tar balls from smoldering biomass combustion, Atmos. Chem. Phys., 10, 6363-6370, doi:10.5194/acp-10-6363-2010, 2010.

Chan, T. W., Huang, L., Leaitch, W. R., Sharma, S., Brook, J. R., Slowik, J. G., Abbatt, J. P. D., Brickell, P. C., Liggio, J., Li, S. M., and Moosmüller H.: Observations of OM/OC and specific attenuation coefficients (SAC) in ambient fine PM at a rural site 
in central Ontario, Canada, Atmos. Chem. Phys., 10, 2393-2411, doi:10.5194/acp-10-2393-2010, 2010.

Chen, Y. and Bond T. C.: Light absorption by organic carbon from wood combustion, Atmos. Chem. Phys., 10, 1773-1787, doi:10.5194/acp-10-1773-2010, 2010.

Cheng, Y., He, K. B., Duan, F. K., Zheng, M., Ma, Y. L., Tan, J. H., and $\mathrm{Du}, \mathrm{Z}$. Y.: Improved measurement of carbonaceous aerosol: evaluation of the sampling artifacts and inter-comparison of the thermal-optical analysis methods, Atmos. Chem. Phys., 10, 8533-8548, doi:10.5194/acp-10-8533-2010, 2010.

Cheng, Y., He, K. B., Duan, F. K., Zheng, M., Du, Z. Y., Ma, Y. L., and Tan, J. H.: Ambient organic carbon to elemental carbon ratios: influences of the measurement methods and implications, Atmos. Environ., 45, 2060-2066, 2011.

Chen, Y. J., Zhi, G. R., Feng, Y. L., Liu, D. Y., Zhang, G., Li, J., Sheng, G. Y., Fu, J. M.: Measurements of black and organic carbon emission factors for household coal combustion in China: implication for emission reduction, Environ. Sci. Technol., 43, 9495-9500, 2009.

Chow, J. C., Watson, J. G., Pritchett, L. C., Pierson, W. R., Frazier, C. A., and Purcell, R. G.: The DRI Thermal/Optical Reflectance carbon analysis system: description, evaluation and applications in U.S. air quality studies, Atmos. Environ., 27A, 1185-1201, 1993.

Chow, J. C., Watson, J. G., Crow, D., Lowenthal, D. H., and Merrifield, T.: Comparison of IMPROVE and NIOSH carbon measurements, Aerosol Sci. Technol., 34, 23-34, 2001.

Chow, J. C., Watson, J. G., Chen, L. A., Arnott, W. P., and Moosmüller, H.: Equivalence of elemental carbon by thermal/optical reflectance and transmittance with different temperature protocols, Environ. Sci. Technol., 38, 4414-4422, 2004.

Chow, J. C., Watson, J. G., Doraiswamy, P., Chen, L. A., Sodeman, D. A., Lowenthal, D. H., Park, K., Arnott, W. P., and Motallebi, N.: Aerosol light absorption, black carbon, and elemental carbon at the Fresno Supersite, California, Atmos. Res., 93, 874-887, 2009.

Clarke, A., McNaughton, C., Kapustin, V., Shinozuka, Y., Howell, S., Dibb, J., Zhou, J., Anderson, B., Brekhovskikh, V., Turner, H., and Pinkerton, M.: Biomass burning and pollution aerosol over North America: organic components and their influence on spectral optical properties and humidification response, J. Geophys. Res., 112, D12S18, doi:10.1029/2006JD007777, 2007.

Favez, O., Alfaro, S. C., Sciare, J., Cachier, H., and Abdelwahab, M. M.: Ambient measurements of light-absorption by agricultural waste burning organic aerosols, J. Aerosol Sci., 40, 613620, 2009

Flowers, B. A., Dubey, M. K., Mazzoleni, C., Stone, E. A., Schauer, J. J., Kim, S. W., and Yoon, S. C.: Optical-chemicalmicrophysical relationships and closure studies for mixed carbonaceous aerosols observed at Jeju Island; 3-laser photoacoustic spectrometer, particle sizing, and filter analysis, Atmos. Chem. Phys., 10, 10387-10398, doi:10.5194/acp-10-103872010, 2010.

Gelencsér, A., Hoffer, A., Kiss, G., Tombácz, E., Kurdi, R., and Bencze, L.: In-situ formation of light-absorbing organic matter in cloud water, J. Atmos. Chem., 45, 25-33, 2003.

Gustafsson, O., Kruså, M., Zencak, Z., Sheesley, R. J., Granat, L., Engström, E., Praveen, P. S., Rao, P. S. P., Leck, C., and Rodhe, H.: Brown clouds over south Asia: biomass or fossil fuel com- bustion?, Science, 323, 495-498, 2009.

Hand, J. L., Malm, W. C., Laskin, A., Day, D., Lee, T., Wang, C., Carrico, C., Carrillo, J., Cowin, J. P., Collett, J., and Iedema, M. J.: Optical, physical, and chemical properties of tar balls observed during the Yosemite Aerosol Characterization Study, J. Geophys. Res., 110, D21210, doi:10.1029/2004JD005728, 2005.

Hansen, A. D. A. and Novakov, T.: Real-time measurement of aerosol black carbon during the carbonaceous species methods comparison study, Aerosol Sci. Technol., 12, 194-199, 1990.

Hecobian, A., Zhang, X., Zheng, M., Frank, N., Edgerton, E. S., and Weber, R. J.: Water-soluble organic aerosol material and the light-absorption characteristics of aqueous extracts measured over the Southeastern United States, Atmos. Chem. Phys., 10, 5965-5977, doi:10.5194/acp-10-5965-2010, 2010.

Hoffer, A., Gelencsér, A., Guyon, P., Kiss, G., Schmid, O., Frank, G. P., Artaxo, P., and Andreae, M. O.: Optical properties of humic-like substances (HULIS) in biomass-burning aerosols, Atmos. Chem. Phys., 6, 3563-3570, doi:10.5194/acp-6-3563-2006, 2006.

Husain, L., Dutkiewicz, V. A., Khan, A., and Ghauri, B. M.: Characterization of carbonaceous aerosols in urban air, Atmos. Environ., 41, 6872-6883, 2007.

Jacobson, M. Z.: Isolating nitrated and aromatic aerosols and nitrated aromatic gases as sources of ultraviolet light absorption, J. Geophys. Res., 104, 3527-3542, doi:10.1029/1998JD100054, 1999.

Jacobson, M. Z.: Strong radiative heating due to the mixing state of black carbon in atmospheric aerosols, Nature, 409, 695-697, 2001.

Jeong, C. H., Hopke, P. K., Kim, E., and Lee, D. W.: The comparison between thermal-optical transmittance elemental carbon and Aethalometer black carbon measured at multiple monitoring sites, Atmos. Environ., 38, 5193-5204, 2004.

Kirchstetter, T. W., Novakov, T., and Hobbs, P. V.: Evidence that the spectral dependence of light absorption by aerosols is affected by organic carbon, J. Geophys. Res., 109, D21208, doi:10.1029/2004JD004999, 2004.

Knox, A., Evans, G. J., Brook, J. R., Yao, X., Jeong, C. H., Godri, K. J., Sabaliauskas, K., and Slowik, J. G.: Mass absorption crosssection of ambient black carbon aerosol in relation to chemical age, Aerosol Sci. Technol., 43, 522-532, 2009.

Krecl, P., Strom, J., and Johansson, C.: Carbon content of atmospheric aerosols in a residential area during the wood combustion season in Sweden, Atmos. Environ., 41, 6974-6985, 2007.

Lack, D. A., Cappa, C. D., Baynard, T., Massoli, P., Covert, D. S., Sierau, B., Bates, T. S., Quinn, P. K., Lovejoy, E. R., and Ravishankara, A. R.: Bias in filter-based aerosol absorption measurements due to organic aerosol loading: evidence from ambient measurements, Aerosol Sci. Technol., 42, 1033-1041, 2008.

Lim, H. J., Turpin, B. J.: Origins of primary and secondary organic aerosol in Atlanta: Results of time-resolved measurements during the Atlanta Supersite experiment, Environ. Sci. Technol., 36, 4489-4496, 2002.

Lim, H. J., Turpin, B. J., Edgerton, E., Hering, S. V., Allen, G., Maring, H., and Solomon, P.: Semicontinuous aerosol carbon measurements: comparison of Atlanta Supersite measurements, J. Geophys. Res., 108, 8419, doi:10.1029/2001JD001214, 2003.

Liousse, C., Cachier, H., and Jennings, S. G.: Optical and thermal measurements of black carbon aerosol content in different en- 
vironments: variation of the specific attenuation cross-section, sigma $(\sigma)$, Atmos. Environ., 27A, 1203-1211, 1993.

Lukács, H., Gelencsér, A., Hammer, S., Puxbaum, H., Pio, C., Legrand, M., Kasper-Giebl, A., Handler, M., Limbeck, A., Simpson, D., and Preunkert, S.: Seasonal trends and possible sources of brown carbon based on 2-year aerosol measurements at six sites in Europe, J. Geophys. Res., 112, D23S18, doi:10.1029/2006JD008151, 2007.

Menon, S., Hansen, J., Nazarenko, L., and Luo, Y. F.: Climate effects of black carbon aerosols in China and India, Science, 297, 2250-2253, 2002.

Petzold, A., Schloesser, H., Sheridan, P. J., Arnott, W. P., Ogren, J. A., and Virkkula, A.: Evaluation of multiangle absorption photometry for measuring aerosol light absorption, Aerosol Sci. Technol., 39, 40-51, 2005.

Pöschl, U.: Atmospheric aerosols: composition, transformation, climate and health effects, Angew. Chem. Int. Ed., 44, 7520 7540, 2005.

Pósfai, M., Gelencsér, A., Simonics, R., Arató, K., Li, J., Hobbs, P. V., and Buseck, P. R.: Atmospheric tar balls: particles from biomass and biofuel burning, J. Geophys. Res., 109, D06213, doi:10.1029/2003JD004169, 2004.

Quincey, P., Butterfield, D., Green, D., Coyle, M., and Cape, C. N.: An evaluation of measurement methods for organic, elemental and black carbon in ambient air monitoring sites, Atmos. Environ., 43, 5085-5091, 2009.

Ram, K. and Sarin, M. M.: Absorption coefficient and site-specific mass absorption efficiency of elemental carbon in aerosols over urban, rural, and high-altitude sites in India, Environ. Sci. Technol., 43, 8233-8239, 2009.

Ramanathan, V. and Carmichael, G.: Global and regional climate changes due to black carbon, Nat. Geosci., 1, 221-227, 2008.

Ramanathan, V., Crutzen, P. J., Kiehl, J. T., and Rosenfeld, D.: Aerosols, climate, and the hydrological cycle, Science, 294, 2119-2124, 2001.

Rattigan, O. V., Dirk Felton, H., Bae, M. S., Schwab, J. J., and Demerjian, K. L.: Multi-year hourly $\mathrm{PM}_{2.5}$ carbon measurements in New York: diurnal, day of week and seasonal patterns, Atmos. Environ., 44, 2043-2053, 2010.

Reisinger, P., Wonaschütz, A., Hitzenberger, R., Petzold, A., Bauer, H., Jankowski, N., Puxbaum, H., Chi, X., and Maenhaut, W.: Intercomparison of measurement techniques for black or elemental carbon under urban background conditions in wintertime: influence of biomass combustion, Environ. Sci. Technol., 42, 884889,2008

Rice, J.: Comparison of integrated filter and automated carbon aerosol measurements at research triangle park, North Carolina, Aerosol Sci. Technol., 38, 23-36, 2004.

Sandradewi, J., Prévôt, A. S. H., Weingartner, E., Schmidhauser, R., Gysel, M., and Baltensperger, U.: A study of wood burning and traffic aerosols in an Alpine valley using a multi-wavelength Aethalometer, Atmos. Environ., 42, 101-112, 2008.

Schauer, J. J., Mader, B. T., DeMinter, J. T., Heidemann, G., Bae, M. S., Seinfeld, J. H., Flagan, R, C., Cary, R. A., Smith, D., Huebert, B. J., Bertram, T., Howell, S., Kline, J. T., Quinn, P., Bates, T., Turpin, B., Lim, H. J., Yu, J. Z., Yang, H., and Keywood, M. D.: ACE-Asia intercomparison of a thermal-optical method for the determination of particle-phase organic and elemental carbon, Environ. Sci. Technol., 37, 993-1001, 2003.
Schnaiter, M., Horvath, H., Möhler, O., Naumann, K. H., Saathoff, H., and Schöck, O. W.: UV-VIS-NIR spectral optical properties of soot and soot-containing aerosols, J. Aerosol Sci., 34, 14211444, 2003.

Schnaiter, M., Linke, C., Möhler, O., Naumann, K. H., Saathoff, H., Wagner, R., Schurath, U., and Wehner, B.: Absorption amplification of black carbon internally mixed with secondary organic aerosol, J. Geophys. Res., 110, D19204, doi:10.1029/2005JD006046, 2005.

Schnaiter, M., Gimmler, M., Llamas, I., Linke, C., Jäger, C., and Mutschke, H.: Strong spectral dependence of light absorption by organic carbon particles formed by propane combustion, Atmos. Chem. Phys., 6, 2981-2990, doi:10.5194/acp-6-2981-2006, 2006.

Sharma, S., Brook, J. R., Cachier, H., Chow, J., Gaudenzi, A., and Lu, G.: Light absorption and thermal measurements of black carbon in different regions of Canada, J. Geophys. Res., 107, 4771, doi:10.1029/2002JD002496, 2002.

Shen, G. F., Wang, W., Yang, Y. F., Ding, J. N., Xue, M., Min, Y. J., Zhu, C., Shen, H. Z., Li, W., Wang, B., Wang, R., Wang, X. L., Tao, S., and Russell, A. G.: Emissions of PAHs from indoor crop residue burning in a typical rural stove: emission factors, size distributions, and gas-particle partitioning, Environ. Sci. Technol., 45, 1206-1212, 2011.

Snyder, D. C. and Schauer, J. J.: An inter-comparison of two black carbon aerosol instruments and a semi-continuous elemental carbon instrument in the urban environment, Aerosol Sci. Technol., 41, 463-474, 2007.

Snyder, D. C., Rutter, A. P., Collins, R., Worley, C., and Schauer J. J.: Insights into the origin of water soluble organic carbon in atmospheric fine particulate matter, Aerosol Sci. Technol., 43, 1099-1107, 2009.

Subramanian, R., Khlystov, A. Y., and Robinson, A. L.: Effect of peak inert-mode temperature on elemental carbon measured using thermal-optical analysis, Aerosol Sci. Technol., 40, 763-780, 2006.

Subramanian, R., Roden, C. A., Boparai, P., and Bond, T. C.: Yellow beads and missing particles: trouble ahead for filter-based absorption measurements, Aerosol Sci. Technol., 41, 630-637, 2007.

Sullivan, A. P., Weber. R. J., Clements, A. L., Turner, J. R., Bae, M. S., and Schauer, J. J.: A method for on-line measurement of water-soluble organic carbon in ambient aerosol particles: results from an urban site, Geophys. Res. Lett., 31, L13105, doi:10.1029/2004GL019681, 2004.

Sun, Y. L., Zhang, Q., Zheng, M., Ding, X., Edgerton, E. S., and Wang, X. M.: Characterization and source apportionment of water-soluble organic matter in atmospheric fine particles $\left(\mathrm{PM}_{2.5}\right)$ with High-Resolution Aerosol Mass Spectrometry and GC-MS, Environ. Sci. Technol., 45, 4854-4861, 2011.

Turpin, B. J. and Huntzicker, J. J.: Identification of secondary organic aerosol episodes and quantitation of primary and secondary organic aerosol concentrations during SCAQS, Atmos. Environ., 29, 3527-3544, 1995.

Venkataraman, C., Habib, G., Eiguren-Fernandez, A., Miguel, A. H., and Friedlander, S. K.: Residential biofuels in south Asia: carbonaceous aerosol emissions and climate impacts, Science, 307, 1454-1456, 2005.

Wang, Q., Shao, M., Zhang, Y., Wei, Y., Hu, M., and Guo, S.: 
Source apportionment of fine organic aerosols in Beijing, Atmos. Chem. Phys., 9, 8573-8585, doi:10.5194/acp-9-8573-2009, 2009.

Wang, Z. H., Bai, Y. H., and Zhang S. Y.: A biogenic volatile organic compounds emission inventory for Beijing, Atmos. Environ., 37, 3771-3782, 2003.

Weber, R. J., Sullivan, A. P., Peltier, R. E., Russell, A., Yan, B., Zheng, M., de Gouw, J., Warneke, C., Brock, C., Holloway, J. S., Atlas, E. L., and Edgerton, E.: A study of secondary organic aerosol formation in the anthropogenicinfluenced southeastern United States, J. Geophys. Res., 112, D13302, doi:10.1029/2007JD008408, 2007.

Weingartner, E., Saathoff, H., Schnaiter, M., Streit, N., Bitnar, B., and Baltensperger, U.: Absorption of light by soot particles: determination of the absorption coefficient by means of Aethalometers, J. Aerosol Sci., 34, 1445-1463, 2003.

Wonaschütz, A., Hitzenberger R., Bauer, H., Pouresmaeil, P., Klatzer, B., Caseiro, A., and Puxbaum, H.: Application of the integrating sphere method to separate the contributions of brown and black carbon in atmospheric aerosols, Environ. Sci. Technol., 43, 1141-1146, 2009.
Yang, M., Howell, S. G., Zhuang, J. and Huebert, B. J.: Attribution of aerosol light absorption to black carbon, brown carbon, and dust in China - interpretations of atmospheric measurements during EAST-AIRE, Atmos. Chem. Phys., 9, 2035-2050, doi:10.5194/acp-9-2035-2009, 2009.

Zhang, J., He, K. B., Shi, X. Y., and Zhao, Y.: Comparison of particle emissions from an engine operating on biodiesel and petroleum diesel, Fuel, 90, 2089-2097, 2011.

Zhang, T., Claeys, M., Cachier, H., Dong, S. P., Wang, W., Maenhaut, W., and Liu, X. D.: Identification and estimation of the biomass burning contribution to Beijing aerosol using levoglucosan as a molecular marker, Atmos. Environ., 42, 7013-7021, 2008.

Zhang, X., Hecobian, A., Zheng, M., Frank, N. H., and Weber R. J.: Biomass burning impact on $\mathrm{PM}_{2.5}$ over the southeastern US during 2007: integrating chemically speciated FRM filter measurements, MODIS fire counts and PMF analysis, Atmos. Chem. Phys., 10, 6839-6853, doi:10.5194/acp-10-6839-2010, 2010. 